\title{
Caring of Old: Carer's Perspective
}

\author{
Bhavna Mehta*, Sweta Parekh \\ Faculty of Social Work, The Maharaja Sayajirao University of Baroda, India
}

\begin{abstract}
The burden of aging society and concern towards the shift in young-old population balance is felt throughout the world. The increasing proportions of older persons have been accompanied, in most populations, by steady declines in the proportion of young persons (UN, 2013). Population of over 60 years olds will reach to one billion within the decade estimates report prepared by UNFPA and Help Age International, 2012. In India too, the pressure is mounting with the increased number of 'Older' people $(60+$ years) by 54.77 percent in the last 15 years. Older People are now living longer with increasing life expectancy and availability of better health facilities but are also requiring more assistance or care to manage their day to day activities. There are many challenges in providing better quality of life to older people especially those requiring high support needs. Older people as a group are also divers and each of them have a distinct need. Carers of older person play a key role in meeting these challenges. Caregivers represent an important source of care for older person and are present in some form in all societies. A caregiver is someone who assumes responsibility for the care of an older person who has some health problems. In Indian context, this role is usually played by family member /members mainly female spouse, daughter in law, son or daughter. The role of caregiver can become increasingly burdensome if the person needs constant care. However, as older persons have many assets, strengths and resources, they can be used, involved in the process of providing care. The aim of this article is to provide an overview of the issues/problems faced by caregivers, level of stress experienced by them in their family relationship and adjustment, burden in different areas of family functioning, social and emotional reactions of caregivers to the responsibility of care giving. The paper is based on the findings of an empirical qualitative in-depth study conducted in the state of Gujarat, India during the year 2012-13. The study concludes that care giving role is a serious and ongoing process. Caregivers often face hardships of various kinds. Daily activities of the care giving coupled with lack of social and familial support causes burden of care, stress and frustration and greatly affect care givers contributing to negative adaptation to the situation thus affecting the their total quality of life. In spite of this carers found lot of satisfaction in the role of carer and carried it out
\end{abstract}

as a sense of their duty to give back.

Keywords Care of Older Persons, Family Relationship and Adjustment, Burden of Care

\section{Introduction}

Old Age is a universal phenomenon and every object on this earth undergoes the process of ageing. In the human society, old age is considered as a social phenomenon rather than physiological. Population of over 60 years olds will reach to one billion within the decade estimates report prepared by UNFPA and Help Age International, 2012.

In India too, the pressure is mounting with the increased number of 'Older' people (60+ years) by 54.77 percent in the last 15 years. This has begun the feeling of the burden of an ageing society. Older People are now not only living longer with increasing life expectancy and availability of better health facilities but are also requiring more assistance or care to manage their day to day activities. Even though nearly a tenth of India's population comprises of older adults, it is impossible to draw a uniform picture of older adults across the country due to the varied and complex nature of the demographic transition in India (Aliyar and Rajan, 2008).

Thus, one of the biggest demographic issues emerging at the global level today is the growth of the older population, and demands that older people care will place on family members and health care systems. With this kind of scenario, there is pressure on all aspects of care for the older persons, be it financial, health or shelter. On account of higher life expectancy and the epidemiological transition that led to a move from infectious diseases to chronic diseases among the community, the care needs, especially healthcare needs of older person have become more pronounced (WHO, 2010).

For most of the nation's history, caring for the older person was a family affair carried out largely by women in the home and caregiving usually takes place within the family setting. It can also be very fulfilling and many are glad to be "giving something back" especially if it is to a parent who once cared him/her. But there is no denying that it can sometimes feel as though they are labouring under an 
intolerable burden. Being a carer is very stressful and very tiring. It is very seldom, even in the best regulated and closest of families, that the burden of caring seems to be shared equally amongst the family members.

The positive aspect is caregivers are sometimes motivated to provide care for several reasons like sense of love or reciprocity, spiritual fulfilment, a sense of duty, guilt, social pressures alike (Eisdorfer, 1991). Carers are essential source of support to older people and take responsibility of most of their needs. Although many carers find aspects of the caring role satisfying, they feel that enjoying togetherness, sharing activities, feeling a reciprocal bond, spiritual and personal growth, increased faith, and feelings of accomplishments and mastery are factors which motivate them to care for older person. In an effort to provide the best possible care for a family member, caregivers often sacrifice their own physical and emotional needs. The emotional and physical experiences involved with providing care can strain even the most capable person. The more challenging the older person's needs, the more complex, demanding and stressful the caregiver's role might be. Therefore, caregivers face many obstacles as they have to balance between caregiving with other demands, including child rearing, career and relationships. One of the negative consequences of caregiving is "caregiver burden," which has been defined as "the physical, psychological or emotional, social and financial problems that can be experienced by family members caring for impaired older adults" (George \& Gwyther, 1986). Despite feelings of satisfaction from their care, caregivers can sometimes feel burdened, socially isolated, strained, and hopeless. They often lack social contact, support \& experience feelings of social isolation. They feel that their role is not generally appreciated by others and often becomes socially invisible. Sometimes long care with commitment and continued responsibility carries frustrations that affect the quality of life and well-being of the caregiver. They tend to sacrifice their leisure pursuits and hobbies, to restrict time with family \& friends and to give up or reduce employment. Caregivers feel that even though proper care and protection is given, the older person has only complaints. They want to rule everything according to their wish and if it doesn't happen the way they want, then they show quarrelsome behaviour (Macneil\& et. al 2010). With the increasing age, older people tend to behave like a kid, argue more, stubborn, have more expectations and depend on others. At times they believe that caring for someone can affect relationships with that person and other people to whom you are close. When someone who was previously fit and healthy becomes dependent due to some or other problems like illness, the power balance shifts and roles within a family inevitably change. At the same time, some relationships are fortified by the intimacy and closeness that caring brings. Sometimes caregivers feel like caring as a second job. Therefore, caregiving is a very engaging task and often results in subjective feelings such as abandonment and demoralization (Pinquart \& Sorenson, 2003, 2005). Because of all these reasons, it is very common at times for caregivers to feel anger, frustration, guilt, isolation, unhappiness in marriage, anxiety, depression a diminished social life, loss of self-esteem from time to time and dissatisfaction with life. When caring becomes complex and taxing, it has the potential to affect the physical and mental health of caregiver. This dilemma is going to increase in the future, as the family structure becomes more and more vertical in shape. Problems become multiple when there is an older person in the home requiring constant care.

\section{The Context}

In a country like India, typically caring of older persons, sick, widow, disabled person is usually seen as the responsibility of the family among Hindus. With the rise in industrialization, urbanization and globalization, old systems of joint family living, Jajmani system (where head of the community take care of needy) have lost its importance and traditional role. However, the recent studies have shown that traditional joint family set up seems to be slowly making a comeback in India. Census 2011 data shows that joint families in the city of Mumbai have grown more by $56 \%$ in past 10 years. While this may be mainly due to economic compulsions and convenience -cost of living, there are some very important reasons why most of the time even today children of Hindu families decide or choose to be carer of their parents - live with them and provide care.

Though love, emotional bonding should be primary reasons, societal expectations and fear of social ostracizing also play a major role in the society like India. Studies have found that spiritual beliefs in Karma theory, values, 'sanskaras' also play a dominant role in children taking care of their old ones as serving one's parents is one's moral duty (dharma) religion, regardless of what that relationship may be. The more a person practices this, the happier he/she will be. Serving the older person will give happiness. If you give happiness to your parents, you too will receive happiness. Those who make their parents happy will never be unhappy. Therefore, service to Parents is described as the best service in Hinduism. There is a Religious Text that equates parents with Gods:

"Matru Devo Bhav; Pitru Devo Bhav; Rendering services to Parents has been described as 'pitra-rin' - a loan from the parents. It is the duty of every child to repay this loan or debt in adult life. (Deloitte, 2014)

\section{About the Study}

Providing care to someone especially the older person whether full time part time, formal, informal or long distance is difficult, both physically and emotionally. Traditionally, families have been the core source of social, economic, 
instrumental and emotional support for the older person in India but modernization, migration of children and smaller family units reflect that this source is eroding (Bloom et al, 2010). It is widely accepted that adult children or caregiver take on the primary responsibility of caring for older parents with acute needs. Therefore, it is very important to know who these care givers are. A caregiver has been defined as a family member who has been living with the older person and be closely involved in his/her activities of daily living, health care.

This paper is based on a primary research conducted in the city of Vadodara- situated in the western part of India in the state of Gujarat. The paper attempts to identify the nature of relationship and intensity of the problems faced by carers of older person, family and adjustment, burden in different areas of family functioning, social and emotional reactions of caregivers to situation they are in. This present research is important as it throws light on the issues and problems related to care of older person. It hopes that the various perspectives of carers of older person would offer moral \& human support for the welfare of the caregivers.

\section{Methodology}

The study was conducted during the year 2012-13. It is descriptive as well as exploratory in nature and has used a structured interview schedule to gather data. Information from 40 carers who were above the age of 50 years was sought. The respondents were diverse in terms of their ethnicity, sex and socioeconomic level. A single (unmarried/ widowed/ separated) older person (above the age of 65 years) who was living with his or her son's or daughter's family, and whose primary carer was a family member were included in the study. The study protocol included questions on personal background of the respondents, how the carers adjust with the family \& maintain positive relationship, their burden in different areas of family functioning, their social and emotional reactions were also included.

Quota sampling method was used to draw the sample for the study. This was because of non-availability of any records related to the number of carers living in families. Information from 40 carers who were taking care of single older person living with them was included in the study. Suitable tools were designed for data collection before setting out for fieldwork. Keeping in view the composition of the universe of investigation, it was decided to use the interviewing techniques. The study included quantitative as well as qualitative approach to data collection.

The quantitative components were explored through the interview schedule which was drafted on the basis of major variables, parameters and objectives of the study. This consisted of open and closed ended questions, which were validated for their content and tested for reliability.

The interview schedule was prepared after the review of existing literature on the subject and the information gained through discussion with research guide in the field. The data was collected through one to one interview method, as it was expected to maintain confidentiality and bring out more genuine answers. As the study required gaining an insight into the respondent's experiences, perception and needs open ended questions were included. This ensured that the respondent could express themselves freely and information gained was not lost. The tools once prepared in English were translated into local language so that the respondents could understand and express themselves in the language they were most fluent and comfortable with. The pretesting of tools was done in order to test their efficacy in the field setting.

Based on the experience of the pilot testing, changes were incorporated in the final interview schedule. The qualitative aspects were studied using the observation method. The interview schedules administered on carers of older person were edited, codified and tabulated. Quantitative data was processed and analyzed using MS Excel Program whereas qualitative data analysis included drawing up of categories and trends within respective domains.

\section{Major Findings of the Study}

This section has been divided into six sub sections according to the study objectives.

\section{Personal Background of the Respondents}

Providing support for older people to continue living at home, including help with domestic tasks, personal care, shopping, or other activities is very important. This all is mostly done by caregivers.

The study found that most of the carers were Hindu (90 percent and other 10 percent included respondents who were Jains and Buddhists) female above the age of 50 years. One third of them were well qualified (graduates and above) and almost half of them were working outside home to earn (47.5 percent).

\section{Information Regarding Carers Family Relationship and Adjustment}

Family is one and only place where one's life begins and love never ends. There are lots of people in one's life, but you won't find a single person in life who care the most like parents. Therefore, having healthy relationships with family members is very important.

(i). The study found that 40 percent of carers were taking care of older person since 11-20 years \& older person had been living with them since 21-30 years. They felt that enjoying togetherness, sharing activities, feeling a reciprocal bond, spiritual and personal growth, increased faith, and feelings of accomplishments and mastery were factors which motivated them to care for older person.

(ii). It was found that majority of the carers ( 62.5 percent) 
sought advice \& guidance from older person before doing any important familial tasks and issues pertaining like relationships, family matters, health, career \& legal matters.

They believed that giving respect to older person by considering their important decisions were very important at the same time it helped in avoiding quarrels in the families. However, few of the Carers believed that seeking older person's advice or decision was inappropriate as they interfere in personal matters, having old \& orthodox thinking, no freedom etc. They often liked to take advice from other family members, friends or relatives.

(iii). Many of the carers opined that majority of the older person ( 82.5 percent) liked to live with them as older person did not have a habit of living with other children or relatives. The reason being older persons were very much emotionally attached with their son and daughter in law as they were living with them since long and were not comfortable with the new environment, surroundings.

Carers believed that attachment was a feeling that thrives on tender feelings of love and compassion, and family was possibly the biggest source of attachment for anybody.

(iv). It was found that majority of the older persons (90 percent) were not working any more. Many of them i.e. 57.5 percent had some source of income from agriculture, pension etc. but felt that the amount received was not sufficient to satisfy their needs. So, carers were helping them financially to live with dignity and respect.

Carers strongly believed that it was important to always admire the older person's feelings. It may not mean anything to you but it may mean everything to them.

(v). Very few older people's relatives visited them (25 percent) once in a year. Carers felt that regular contact of children could be beneficial to older person in many ways but loss of social contact led to loss of intimacy, which further exacerbates loneliness, isolation and depression. Therefore, carers believed that communication was the best way to create strong relationships.

(vi). Carers opined that majority of the older person (75 percent) had health problems but were quite capable of doing day to day activities as older people were taking care of their diets and were exercising regularly. They were doing this not only to increase their longevity, but also to increase the number of healthy and active years of life. But, very few were not able to carry out day to day activities.

(vii). Majority of the carers (70 percent) especially those who careres who were home makers opined that the services that they were providing to older person were very much satisfying and older person lived comfortably with them because they had an intimate bond or attachment with the carer and family. The carer felt that they were living with them since long so it's their duty and responsibility to help older person during his/her difficult times. But, sometimes they found constant demands made by older person were exhausting them. They felt that they were also human beings and they also got tired as only one person was responsible to handle older person as well as household work and family members too.

(viii). Carers opined that majority of the older person (65 percent) got angry or show quarrelsome behavior in the family. They often behaved like a child. They opined that older person used to get angry or irritated on silly things / matters and had become very sensitive, adamant. Carers revealed that even though they gave proper care and protection, the older person had only complaints. The family members also viewed that the older person want to rule everything as per their wish and if it was not done according to their wish, they show quarrelsome behavior.

(ix). Majority of the carers (62.5 percent) felt that older person presence doesn't create any disturbance for the family members and they liked to take care of older person because they considered them as a member of the family and they were very much emotionally attached to older person. They always felt that caring for older person was one type of blessing for them which hold a lot of meaning in their life.

(x). 62.5 percent of the carers opined that there were many changes in behaviour of older person with the increasing age. They felt that anger, dissatisfaction with each and everything, dominating, screaming, wandering, suspiciousness, arguing, childlike, stubbornness, more emotional, more expectations, more dependency, keeping quiet, feeling lonely, forgetfulness were some of the characteristics of older person with increasing age.

\section{Information Regarding Carers Facing Burden in Different Areas of Family Functioning}

Caregiving burden as the stress was perceived by caregivers due to the home care situation. Caregivers were all persons who support and help a person in need of care regularly because of personal - not professional - reasons. Caregiver burden comes out when the caregiver perceives the home care situation as a negative experience.

(i). Majority of the carers ( 92.5 percent) who were home makers responded that they got enough time to perform household chores and enough time to look after the needs of children as well as to look after the other members of the family. Carers felt that it was a good chance that she could be a caregiver to more 
than one person during her lifetime. They gain a sense of satisfaction from a job well done, or because they were fulfilling their duty or obligation to the care recipient and other members of the family. Whereas those women carers who also worked outside home found themselves at times juggling with multiple responsibilities. Though they valued their relationship with older person, wished, hoped and loved to do their best meeting demands put on them, these carers regretted for accepting the role of carer thrust upon them. There were two women (5 percent) of women who had quit their job as they found themselves unable to keep with the pace of demands put on them at home.

(ii). Many of the carers (65 percent) in this study spent time for leisure activity such as hearing radio, playing cards, listening to music. Some of the respondents mainly working women also revealed that they spent most of the time by simply chatting with others or by doing nothing or by sitting idle and taking rest. They felt that leisure time activities helped them in relieving stress.

(iii). The study showed that majority of the carers $(80$ percent) received negligible support from family members in carrying out the household chores as well as in caregiving process but family relationship had not been affected due to caring of older person. Other family members helped the carer as and when they got time. They believed that healthy family relationships help all members of a family feel safe and connected to one another.

While all families go through good and difficult times, a family with healthy relationships are still able to interact with one another in a safe and respectful way. At the same time, they don't even felt that their work had doubled due to caring of older person.

(iv). Many of the carers (60 percent) opined that they were constantly worried and bothered behind their mind about their role as carer of older person. They felt that there were a lot of things they could do to make the caregiving process easier for both of them. Many caregivers found themselves giving round-the-clock care, or spending virtually every free moment attending to the needs of their older person. Others found that their responsibilities were less constant, but never knew if it would be needed at any moment or the next, so they felt like they need to be constantly available. The feeling of being "always on duty" could sometimes take heavy responsibilities on a caregiver.

\section{Information Regarding Social and Emotional Reactions of Caregivers}

Whether one become a caregiver gradually or all of sudden due to a crisis, or whether it is willingly or by default, many emotions surface when one takes on the job of caregiving. Some of these reactions happen immediately and some don't surface until one become caregiving for a while.

(i). Majority of the carers (70 percent) opined that they don't feel socially isolated but many carers (65 percent) received less social support from family members to take care of older person. They needed to balance caregiving with their other activities, such as work, family \&sometimes found it difficult to focus on the positive aspects of caregiving and often experienced more negative reactions, such as an increased sense of burden. They believed that social support could be one way to minimize the negative outcomes of caregiving.

(ii). Majority of the carers (72.5 percent) didn't find any difficulty in social interaction and interpersonal relationship (87.5 percent). They believed that social interaction plays an important role in maintaining a caregiver's health by providing an opportunity for communication and an outlet for emotional expression.

(iii). Almost half of carers (52.5 percent) got angry or found themselves restless or hostile while caring for the older person. The reasons were having to be the carer, the extra responsibilities, having future plans interrupted, had little or no time for activities they used to enjoy, feeling the person they're caring for does not seem to appreciate the hard work and sacrifices being made. They believed that their life did not belong to them and they had no control.

(iv). 50 percent of carers were fed up with the caregiving process. They felt more fatigue \& worried about how they would be able to handle the additional responsibilities of caregiving and what would happen to their family member if something happens to the carers. At the same time, they felt that being worried about future was not going to help them instead they could live in present and enjoy their life by balancing in life and begin to do what they liked to do.

(v). The study also found that almost half of carers (47.5 percent) had lost interest in providing caregiving to older person. Caregivers felt that they had to take whole responsibility for everything and later on this lead to conflicts. Caregivers felt like older person were constantly giving orders, nagging, and questioning. Because of this, they showed lack of interest, irritation and decline in motivation.

\section{Information Regarding Level of Stress Experienced by Caregivers}

Caring for an older person could be among the most fulfilling experiences for any family caregiver. So many tasks bring pleasure as one gives back to someone who may have given you so much. However, even as carer lovingly provides support to an older person, one may have problems managing and balancing that support with one's own busy 
life. The responsibilities could impact physically, mentally and emotionally. And that could lead to the kind of distress that could result in serious health problems.

(i). The study shows that many carers (55 percent) faced health problems like high blood pressure, (42.5 percent) headache $\&$ ( 40 percent) faced problem of muscle ache and pain. Carers believed that this all was because of inadequate time for sleep, self-care, tension, stress fatigue, anxiety, headache which leads to health related problems. They expressed that disturbed night, emotional worry, isolation had affected their daily routine.

(ii). Some of the carers reported of becoming moody ( 40 percent), irritated (37.5 percent), anxious (25 percent), depressed (35 percent), angry (30 percent), emotional (30 percent), withdrawn (32.5 percent), less tolerant etc. They felt that this was happening to them because at times it became difficult for them to cope with the situations. Some of them said that as they were very sensitive people and took things very seriously to heart, it had resulted in frustration.

(iii). Few of the carers (17.5 percent) gossiped about others because they felt that gossip was a natural human instinct. It may even boost one's endorphins, warding off stress and increasing our immunity. But, of course, not all gossip was beneficial, especially when closely held details are revealed or someone shares secrets just to feel superior. They believed that caregiver needs to be more patient, compassion, and a natural talent in providing care. But sometimes patience was not enough, they need someone to whom they could share their problems and because of that they criticize others to outburst their feelings.

\section{Information Regarding Problems Faced by Caregivers}

Many of us would become the caregiver of a parent or loved one. It's a rewarding endeavour, but it could be filled with enormous challenges. Let us see what problems were faced by caregivers in this study.

(i). Most of the working women carers (65 percent) faced trouble in handling things \& difficulty in making important decisions in life because they felt that one of the biggest struggles caregivers face was dealing with the difficult behaviours of the person they were caring for. At the same time, they also believed that breaking down the activities into series of steps could help manage the work. They also believed that patience and compassion helps them to manage things easily.

(ii). The study shows that some of the carers (40 percent) at times felt completely overwhelmed, felt lonely, sense of loss of privacy. They felt that the brain was so overwhelmed with stress that it actually reduces the energy. Some people experience such a feeling of emotional distress that they may start to cry or feel like they're about to cry, 40 percent couldn't even sleep while others may experience a complete lack of hope as if their anxiety was never going to be treatable.

\section{Conclusions}

While Care giving of old family member gave lot of satisfaction and sense of being, doing their 'Dharma', 'Duty' to most of the carers, they often faced hardships of various kinds like lack of social support, family support, burden, stress, frustration, unable to cope with daily activities of the caregiver especially when care givers were daughter in laws. These greatly contributed to negative adaptation to the situation thus affecting the caregiver's overall quality of life. Women carers sometimes faced psychosomatic health problems due to the stress of handling lot of work at various fronts - home, familial as well as societal responsibilities. They sometimes found themselves unable to cope with the situations resulting in frustration.

Looking at the caregiver's family relationship and adjustment, it was found that carers were taking care of older person since 11-20 years as they were now so much attached that they always gave respect to older person's decision and sought guidance/advice from them. Because of those attachments, older person didn't want to live with other children. Carers felt that older persons were very much satisfied with the service provided by them and did not feel disturbed with older person living with them. There were times, when comparatively those women carers who worked outside home felt more stressed and troubled due to their work own pressures coupled with the changes in behaviour of older persons troubling them, bothering them. They sense of 'being on duty' all the time emerged as the major concern.

The study also observed that majority of the carer's got enough time to perform household chores as they sometimes got support from family members in carrying out the household activities as well as in caregiving process \& family relationship had not been affected due to caring of older person. They believed that healthy family relationships help all members of a family feeling safe and connected to one another. They got enough time to look after the needs of children as well as to look after the other members of the family. Male carers though included less in this study got time for leisure activity such as hearing radio, playing cards, listening music than women care givers.

Normally, social and emotional reactions of caregivers vary dramatically from day to day. As the carers who worked outside home needed to balance work and home responsibilities alone and due to that they expressed emotions such as sadness, anger, depression, and feelings of overwhelmed. Because of all this reasons, they found difficulty in maintaining social contact or difficulty in social interaction with others.

Finally, they were so much fed up with the caregiving 
process because older person was always ordering, nagging and questioning. As a result, all of the emotions ran through them. Carers found themselves at times unable to cope with the situations, took the role so seriously that it affected them negatively. Care givers expressed their need to talk gossip and ventilate their frustrations with someone and found it to be healthy way to cope with the stress of caregiving.

Carers felt very lonely and loss of privacy and because of that, they found difficulty in making important decisions in life as they recognized that the biggest struggle they were facing was dealing with the difficult behaviours of the person they were caring for.

The process and experience of care giving in this study differed between women and man obviously due to gender roles, responsibilities and their access and control over resources. However, between women as a group this study found that working women were caught in the web of multiple roles burdening, stressing them at times. While being a care provider gave them lot of psychological satisfaction, boosting, alleviated their image in their network of relationship it took its toll on their health, interpersonal relationship with spouse and other family members. The cycle of guilt which working women go through due to inability to cope with multiple demands of familial role as a wife, mother, daughter in law gets aggregated when the added role of care giving to an older family member becomes more demanding, energy subsuming and increasing day by day.

Nonetheless caregivers were satisfied with their role without experiencing overwhelmingly negative physical, emotional, or financial consequences. On the other hand, caregivers with the heaviest responsibilities were vulnerable to risk such as decline in health, emotional stress and economic hardships. Therefore, caregiving experiences range from relatively easy to manage, to burdensome.

\section{REFERENCES}

Aliyar S., Rajan, S. (2008). Population Projections for India, 2001-
2101. Thiruvananthapuram: Centre for Development Studies.

Ageing in the Twenty-First Century: A Celebration and A Challenge: Published by the United Nations Population Fund (UNFPA), New York, and Help Age International, London.

Basheer, S; Saif N.R; Minhas, F; Najam, N. (2005). Depression and anxiety in the caregivers of mentally ill patients, JPPS - Journal of Pakistan Psychiatric Society. 2(1): 27.

Bloom, D.E., A. Mahal, L. Rosenberg, and J. Sevilla. (2010). Economic security arrangements in the context of population ageing in India. International social security review 63(3-4): 59-89

Deloitte. (2014). Ensuring care for the golden years - Way forward for India. FICCI $7^{\text {th }}$ Annual Health Insurance Conference retrieved from http://www2.deloitte.com/content/dam/Deloitte/in/ Documents/life-sciences-health-care/in-lshc-ficci-elderly-care-noe xp.pdf on 10th June, 2016

Eisdorfer, C. (1991). Caregiving: an emerging risk factor for emotional and physical pathology. Bull Menninger Clinic.55:238247.

George, L., \&Gwyther, L. (1986). Caregiver Well-being: A Multidimensional Examination of Family Caregivers of Demented Adults. The Gerontologist, 26(3), 253-259.

Gonyea JG; Paris R; de Saxe ZerdenL.(2008). Adult daughters and aging mothers: The role of guilt in the experience of caregiver burden. Aging and Mental Health, 12: 559-67.

Macneil G; Kosberg JI; Durkin DW; Dooley WK; Decoster J; Williamson GM. (2010). Caregiver mental health and potentially harmful care-giving behavior: The central role of caregiver anger. Gerontologist, 50: 76-86.

Pinquart, M., \& Sorensen, S. (2003). Differences between caregivers and non-caregivers in psychological health and physical health: a meta-analysis. Psychology and Aging, 18(2), 250-267.

Pinquart, M., \& Sorensen, S. (2005). Caregiving distress and psychological health of caregivers. In: Oxington, K.V. (Ed.), Psychology of Stress. Nova, Hauppauge, NY, pp. 165-206.

World Health Organization, (2002). Reducing Stigma and Discrimination against Older People with Mental Disorders. Geneva: World Health Organization and World Psychiatric Association; Available: http://whqlibdoc 